Volume 10, No.5, September - October 2021

International Journal of Science and Applied Information Technology

Available Online at http://www.warse.org/ijsait/static/pdf/file/ijsait011052021.pdf

https://doi.org/10.30534/ijsait/2021/011052021

\title{
Program-Based Quality Assurance Model with Decision Support System
}

\author{
Zenaida Taguinod Estil \\ St. Paul University Philippines, Philippines, ztestil@ spup.edu.ph
}

Received Date : August 05, 2021 Accepted Date : September 14, 2021 Published Date : October 06, 2021

\begin{abstract}
Quality education is regarded as an essential provider to the country's economic advancement. This study aimed to design and develop a Program-Based Quality Assurance Model with Decision Support System for St. Paul University Philippines. The researcher created a model and developed a database management tool to assess the quality assurance mechanism employed by the Philippine Accrediting Association of Schools, Colleges and Universities (PAASCU) and Philippine Association of Colleges and Universities Commission on Accreditation (PACUCOA) to ensure a reliable delivery of quality education on the program it provides. The study employed the Rapid Application Development Model for the software development and Quantitative method using descriptive survey was used to gather data. The problems, issues, and challenges in accreditation with respect to preparation, document and records management and reporting were utilized by the researcher for the development of the system. The developed system is a web-based application, thus, can be easily accessed. As a result, the system effectively stores and retrieved data needed for the preparation of documents and records for accreditation. Thus, the features of the developed system were accepted to be useful based on the results of the evaluation in accordance with the software compliance criteria of ISO 25010 Software Quality Standards with overall weighted mean of 4.1212 with a descriptive interpretation of "Great Extent". The developed system can be of great help to the Accreditation Team to monitor accomplishments of all programs along with the recommendations for proper documentation and record keeping.
\end{abstract}

Key words : Accreditation, Program-Based Quality Assurance, Quality Assurance, Records Management.

\section{INTRODUCTION}

Higher education is the backbone of any society. It is the quality of higher education that decides the quality of human resources in a country. [1]In addition, Higher Education is a complex system that facilitates teaching, research, extension, and international cooperation and understanding. (Mishra,2006).
Besides, the quality of higher education contributes to skilled human capital formation that is essential to develop a country's socio-economic competencies. It is often believed that quality education is the key factor in determining the place of a nation in global competition (Materu, 2007).

The European Commission Tempus (2000) stresses that quality assurance has become an increasingly dominant theme in Higher Education Institutions (HEIs) in recent years, with international processes playing an important role in the way in which quality assurance is interpreted and implemented[9]. Thus, Quality Assurance becomes an urgent concern in HEIs.

Quality assurance is the process of verifying whether products or services meet or exceed customer expectations[16]. It is a process-driven approach with specific steps to help define and attain goals. For UNESCO, quality assurance is the systematic review of educational programs to ensure that acceptable standards of education, scholarship and infrastructure are maintained. A quality assurance system in the case of a university is said to increase student confidence and the university's credibility as a provider of quality services to improve processes and efficiency and to enable a university to better compete with others (Pavlenko et al., 2008).

With the opening of college degrees, St. Paul University Philippines [SPUP] became the first accredited institution in the region by the Philippine Accrediting Association of Schools, Colleges and Universities (PAASCU) in 1961.In its efforts towards global and international education, SPUP gained the distinction of being the First Private Catholic University in Asia and the First Private University in the Philippines to be granted ISO 9001 Certification by TUV Rheinland in 2000 and the only University accredited by the Asian Association of Schools of Business International (AASBI) in 2014.

Today, SPUP is recognized by the Commission on Higher Education (CHED) as an Autonomous Institution; Center of Excellence in Nursing, Center of Excellence in Teacher Education; Center of Development in Information Technology; Center of Teacher Training Institution; the first accredited Integrated Basic Education Unit in Cagayan Valley; a deputized institution for the Expanded Tertiary Education Equivalency Accreditation Program (ETEAAP); 
Most Outstanding Student Services in the Philippines; Outstanding Research/Academic Library in the Philippines; and, the Lead School of the St. Paul University System. (SPUP Website,2018.

This study aimed to design and develop a Program-Based Quality Assurance Model with Decision Support System for St. Paul University Philippines. The researcher created a model and developed a database management tool to assess the quality assurance mechanism employed by the Philippine Accrediting Association of Schools, Colleges and Universities (PAASCU) and Philippine Association of Colleges and Universities Commission on Accreditation (PACUCOA) to ensure a reliable delivery of quality education on the program it provides.

The study employed the Rapid Application Development Model for the software development and Quantitative method using descriptive survey was used to gather data. The problems, issues, and challenges in accreditation with respect to preparation, document and records management and reporting were utilized by the researcher for the development of the system. The developed system is a web-based application, thus, can be easily accessed. As a result, the system effectively stores and retrieves data needed for the preparation of documents and records for accreditation

\section{STATEMENT OF THE PROBLEM}

This study aimed to design and develop a Program-Based Quality Assurance Model with Decision Support System for St. Paul University Philippines.

Specifically, it aimed to answer the following questions:

1. What are the problems, issues and challenges encounteredduring accreditation with respect to:
1.1 preparation;
1.2 documents/records management; and
1.3 reporting?

2. What program-based quality model can be designed to serve as basis for the development of the proposed system?

3. What system can be developed to address the problems and challenges in the existing system?

4. What is the extent of compliance of the developed application to ISO 25010 Software Quality Standards in terms of:

4.1 Functional Suitability;

4.2 Performance Efficiency;

4.3 Compatibility;

$4.4 \quad$ Usability;

4.5 Reliability;

4.6 Security;

4.7 Maintainability; and

4.8 Portability?
5. What enhancements can be done to improve the developed system?

\section{PARADIGM OF THE STUDY}

The Input-Process-Output framework illustrates a schematic presentation of the inputs such as the data and/or requirements necessary for system planning that had been analyzed, processed, and, finally, to generate the final output, such as the application for quality assurance.

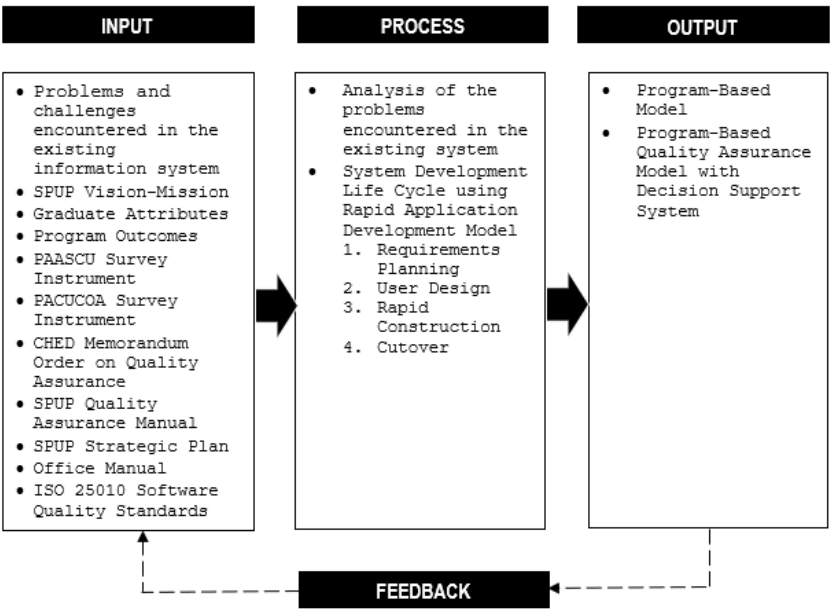

Figure 1: Paradigm of the Study

The paradigm of the study follows the input-process-output diagram with a feedback mechanism. To gather the required inputs needed for the desired system, the following were considered: the problems, issues and challenges encountered in the existing system, SPUP Vision-Mission, Program Outcomes, Graduate Attributes, SPUP Strategic Plan, CHED Memorandum Order on Quality Assurance, SPUP Quality Assurance Manual, and the Office Manual and Procedures and the ISO 25010 Software Quality Standards

The PAASCU survey instrument was also part of the Input since this was used as basis for the development of the QA Decision Support System.[4] The survey instrument served as a guide for institutions as they strive for excellence and for accreditors as they assess institutional achievement. evaluative criteria included the following: [5]Vision, Mission and Goals, Faculty, Curriculum and Instruction, Library, Laboratories, Physical Plant, Student Services, and Administration.

For the process, the researcher considered the following: analysis of the problems, issues and challenges encountered in accreditation, System Development Life Cycle using Rapid Application Development Model which consisted of four (4) stages such as Requirements Planning, User Design, Rapid Construction and Cutover. Lastly, the researcher assessed the developed system using the ISO 25010 software quality standards.

The output of the study is the Quality Model which could serves as the basis for the development of the QA Decision 
Support System. The Feedback mechanism was considered to engage the users in the development and improvement of the system and its implementation.

\section{METHODOLOGIES}

\subsection{Research Design}

The researcher used the descriptive and developmental design methods in the study. The study employed the Rapid Application Development Model for the software development and Quantitative method using descriptive survey was used to gather data. The problems, issues, and challenges in accreditation with respect to preparation, document and records management and reporting were utilized by the researcher for the development of the system.

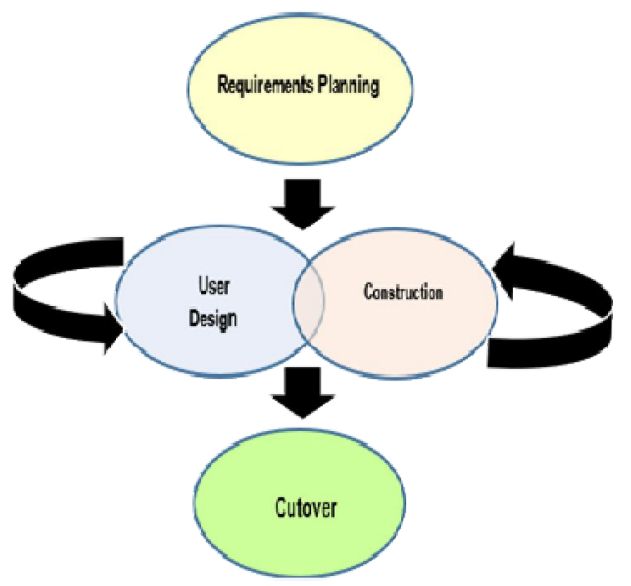

Figure 2. Rapid Application Development Model

\subsection{Research Methods}

To obtain the data needed for the investigation, the following procedures were undertaken by the researcher.

The researcher obtained clearance from the Ethics Review Committee of St. Paul University Philippines to ensure the ethical soundness of the research. The researcher obtained endorsement from the Dissertation adviser and the Dean of the Graduate School for data gathering.

The researcher sought permission from the Office of the Vice-President for Academics to conduct the study.The researcher informed the Quality Assurance Team, Deans, Associate Deans, Program Coordinators, and Unit Heads regarding the collection and gathering of relevant information related to the problems, issues and challenges encountered in the accreditation.

The questionnaire was administered by the researcher to the I.T experts, faculty, and staffs to evaluate the system in terms of quality standard and acceptability.

The researcher informed the Office of the Vice-President for Academics to conduct the study. IT Expert participants were also asked to sign the Informed
Consent Form. The approved letters and forms together with the study proposal was submitted to the St. Paul University Philippines Ethics Review Committee (SPUP-ERC). The study was continued upon receipt of the letter of approval from the university.

\subsection{Data Analysis}

The data were collected, tabulated, summarized, analyzed, and interpreted using the following descriptive statistical tools:

Weighted Mean. This tool was used to analyze the rating of the IT experts on the extent of compliance of the developed system to the ISO 25010 software quality standards.

5-Point Likert Scale. This tool was used to measure the compliance of the developed system ranging from "Very Great Extent" (5) to "Very Low Extent" (1).

Table 1. 5-Point Likert Scale and the Descriptive Interpretation

\begin{tabular}{|c|c|l|}
\hline Scale Range & Rating & Descriptive Interpretation \\
\hline $4.20-5.00$ & 5 & Very Great Extent \\
\hline $3.40-4.19$ & 4 & Great Extent \\
\hline $2.60-3.39$ & 3 & Moderately Extent \\
\hline $1.80-2.59$ & 2 & Low Extent \\
\hline $1.00-1.79$ & 1 & Very Low Extent \\
\hline
\end{tabular}

\section{RESULTS AND DISCUSSION}

\section{A.Problems, Issues, and Challenges Encountered in Accreditation with Respect to Preparation, Document/ Record Management, and Reporting}

The participants encountered the following problems in the accreditation process: poor filing system, limited time to prepare the documents, limited dissemination of information, personnel involved in the preparation. regarding document/record management, compilation and retrieval of documents, lack of systematic filing of records were the problems encountered and with respect to reporting, Writing of reports, consolidation of reports, absences of system for managing records and no cooperation from the different units were identified.

The participants encountered issues and challenges such as consolidation/collation of documents, time management, commitment of people involved in the preparation, no system for storing and retrieval of documents, lack of documentation, no coordination in collecting documents, writing of reports, insufficient evidence.

\section{B.Program-Based Quality Assurance Model}

The model was developed based on data gathered and analyzed in this study. 


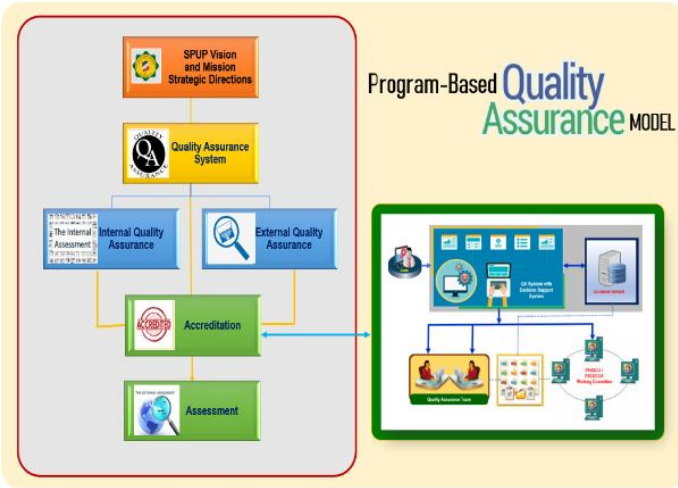

Figure 3. Program-Based Quality Assurance Model

The Program-Based Quality Assurance Model is composed of different components such as SPUP Mission, Vision, Strategic Directions, QA System both Internal and External and lastly the Assessment.

The model is anchored with the Vision, Mission and Strategic Direction of St. Paul University. Quality Assurance System is applied as a mechanism for assuring quality of education offered. It highlights two main components, namely: the Internal and External Quality Assurance.

Internal QA involve self-analysis, quality plan, monitoring and evaluation. It refers to the policies and practices or mechanisms where in institution must monitor and improve the quality of their education provision. This process ensures that the institution fulfill its own purposes as well as the standards. They are informed to formulate and implement QA policy as a guide for assuring quality of activities conducted within institutions.

External QA refers to the action of an external body like any accrediting body which assesses the operation of the institution or its programmes, to determine whether it is meeting the agreed standards. This system includes the mechanism accreditation, review and assessment and evaluation or audit. The aim is to achieve accountability and enhance institutions performance.

The Assessment component is part of the model in order to evaluate the impact and outcomes of the institution.

The developed system is a database management tool used to monitor accomplishments of all programs along with the recommendations for proper documentation and record keeping. It is also used to assess the quality assurance mechanisms employed/implemented in accordance with the criterion provided by the external accreditors to ensure quality education has been attained per program.

\section{C.Program-Based Quality Assurance Model with Decision Support System}

The QA System with DSS is a web-based application that can be easily accessed. [10] It effectively stores and retrieved data needed for the preparation of documents and records for accreditation. This model assesses the quality assurance mechanism employed by the Philippine Accrediting Association of Schools, Colleges and Universities (PAASCU) and Philippine Association of Colleges and Universities Commission on Accreditation (PACUCOA) [3] to ensure quality education has been attained per program. As a result, the system effectively stores and retrieves data needed for the preparation of documents and records for accreditation.

\section{D.Extent of Compliance of the Developed System to the Standards of ISO 25010 Software Quality Standards}

Table 2. Summary on the Extent of Compliance of the Developed Application in Terms of the ISO 25010 Software Criteria

\begin{tabular}{|l|c|c|}
\hline \multicolumn{1}{|c|}{ ISO 25010 Software Criteria } & Mean & $\begin{array}{c}\text { Descriptive } \\
\text { Interpretation }\end{array}$ \\
\hline Functional Suitability & 4.17 & Great Extent \\
\hline Performance Efficiency & 4.10 & Great Extent \\
\hline Compatibility & 4.10 & Great Extent \\
\hline Usability & 4.20 & Very Great Extent \\
\hline Reliability & 4.03 & Great Extent \\
\hline Security & 4.14 & Great Extent \\
\hline Maintainability & 4.12 & Great Extent \\
\hline Portability & 4.20 & Very Great Extent \\
\hline OVERALL MEAN & 4.12 & Great Extent \\
\hline
\end{tabular}

Table 2. shows the overall result of the system evaluation in compliance with the ISO 25010 software quality standards. It shows that the system obtained an overall mean of 4.12 with a descriptive interpretation of "Great Extent".

Results revealed that the developed system complied with ISO 25010 Software Quality Standards to a "Great Extent" in terms of Functional Suitability, Performance Efficiency, Compatibility, Usability, Reliability, Security, and Maintainability while Portability quality requirements obtained a descriptive interpretation of "Great Extent" and as evaluated by the IT experts.

\section{E.Enhancement of the Developed Program-Based Quality Assurance Model with Decision Support System}

Based on the evaluation of the system by the IT Experts, the following are the enhancements that can be done to be improve the developed system:

The Administration may consider server for the system to store big data that will be used for storing, managing, reporting, and maintaining records, reports, and information for accreditation.

There is a need to create a more highly classified network to secure sensitive records.

\section{CONCLUSION}

Based on the findings of the study, the following conclusions were made: 
The developed system can be of great help to the Accreditation Team to monitor accomplishments of all programs along the recommendations for proper documentation and record keeping. Moreover, the use of the tool met the characteristics and requirements of software quality standards defined in ISO/IEC 25010.

\section{CONCLUSION}

Based on the findings and conclusion of the study, the following are recommended:

The researcher may present the developed system to the Administration for its utilization; the Administration may consider proposing a training on the use of the developed system which will be conducted to the personnel assigned to work for the accreditation; the Administration may consider Electronic Document and Records Management System (EDRMS), [2]an application that is used to manage digital information. It is a software that provides a framework for the capture, maintenance, and accessibility of records. Through this system, [5]it can increase efficiency and ensure that records are appropriately managed, secured and accessible. It also provides central repository of records; The Quality Management System Head may consider conducting re-training on office files and records management in order to enhance the knowledge on how to manage and organize records and documents more effectively and to learn how to create an effective and intuitive filing system in a digital format to improve efficiency; the Quality Management Representative may consider giving the heads of units and their staff further training workshop on writing accreditation reports; Future researchers may consider improving the developed system by including the other Survey Forms developed by the different accrediting, certifying and awarding bodies.

\section{REFERENCES}

1. CHED, 2012. Guidelines for the Implementation of CMO46.

2. Mahmood, A. and Okumus, E. (2017). Design and Implementation of Electronic Document Management System. Retrieved from https://dergipark.org.tr/download/article-file/358089

3. Ordonez, V. \& Ordonez, G. (n.d.). Accreditation in the Philippines: A case study. Retrieved from: http://www.victorordonez.com/downloads/readvictor/Ph il_Accreditation_rev_7dn.doc

4. PAASCU. (2006). Primer for Accreditation. Manila: PAASCU.

5. Cho, Ahm (2009). Records Management System Definition and Concepts. sacho@dimsway.com

6. Conchada, I. and Tiongco, M. (June 2015). A Review of the Accreditation System for Philippine Higher Education Institutions. Retrieved from https://dirp3.pids.gov.ph/webportal/CDN/Publications/pi dsdps1530.pdf

7. UNESCO (2006).Higher education in Souteast Asia. The UNESCO Asia and Pacific Regional Bureau for Education.
8. UNESCO, 2005. Guidelines for Quality Provision in Cross-Border Higher Education. Retrieved fomhttp://unesdoc.unesco.org/images/0014/001433/143 349e.pdf last October 2013

9. UNESCO, 2013.2 Website http://www.unesco.org/new/en/education/themes/strengthe ningeducation-systems/higher-education/ Retrieved last October 2013

10. Fakeeh, K. (2015). Decision Support System (DSS) in Higher Education System. International Journal of Applied Information Systems (IJAIS) - ISSN : 2249-0868; Foundation of Computer Science FCS, New York, USA, Volume 9 - No.2, June 2015 www.ijais.orgProduction, $1-9$. Doi:10.1016/j.jclepro.2014.01.074.

11. Laguador, J. et al (2015). Philippine Quality Assurance Mechanism in Higher Education towards Internationalization. Studies in Social Sciences and Humanities. Vol. 3, No. 3, 2016, 1156-157.

12. Padua, R.N. (2003). International higher education quality assurance. Journal of Philippine Higher Education Quality Assurance,

13. Ruiz and Sabio, (2012). Quality Assurance in Higher Education in the Philippines. Asian Journal of Distance Education. ISSN 1347-9008. Asian J D E 2012 Vol 10 no 2,pp 63-70.

14. Yap, J. (2012). "Regional Cooperation in Education: Issues for Developing Countries in the AsiaPacific." Philippine Institute for Development Studies Discussion Papers 2012-15. Retrieved from http://dirp4.pids.gov.ph/ris/dps/pidsdps1215.pdf

15. Ryan, P. (2015). Quality assurance in Higher Education: A Review of Literature. Higher Learning Research Communications,5(4).http://dx.doi.org/10.18870/hlrc.v5 i4.257 